\title{
Analisis Faktor Yang Berhubungan Dengan Perawatan Mandiri Pasien Tuberculosis
}

\author{
Sri Sudewi Pratiwi Sitio ${ }^{(1)}$, Efrata Sembiring ${ }^{(2)}$, Bahtera Bindavid Purba ${ }^{(3)}$ \\ Program Studi Kesehatan Masyarakat Institut Kesehatan Deli Husada Deli Tua ${ }^{(1)(2)(3)}$ \\ Dewisitio08@gmail.com, barensbravo@yahoo.co.id , bahterabd@gmail.com
}

\begin{abstract}
ABSTRAK
Tuberkulosis merupakan penyakit menular kronis dimana Mycobacterium tuberculosis sering menginfeksi paru-paru. Di Puskesmas Langga Payung, Kabupaten Labuhan Batu Selatan tahun 2018, ditemukan 266 kasus positif TB Paru. Dari 266 kasus TB ditemukan 231 kasus (86\%) kasus baru dan ditemukan 35 kasus (13,1\%) MDR-TB. Penelitian ini bertujuan untuk menganalisis faktor-faktor yang berhubungan dengan perawatan diri pada pasien tuberkulosis. Penelitian ini menggunakan metode cross sectional dengan populasi penderita tuberkulosis yang datang ke Puskesmas Langgapayung. Besar sampel ditentukan dengan rumus Lameshow sebanyak 74 kasus TB baru dengan kriteria inklusi: Usia $\leq 50$ tahun, sudah PMO, penderita TB sudah menjalani pengobatan <2 bulan, sistem pembayaran BPJS kesehatan dan kriteria eksklusi: HIV / AIDS, DM, tidak berdaya, dan menolak untuk berpartisipasi. Sampel diambil dengan teknik consecutive sampling. Instrumen penelitian diuji dengan Corbach alfa dan pengolahan data dilakukan dengan metode regresi logistik pada taraf nyata $\alpha=0,05$. Hasil analisis diketahui bahwa ada hubungan antara umur $(\mathrm{p}=0,04 ; \mathrm{p}<0,05) \mathrm{RP}(3,04 ; \mathrm{CI} 95 \%$ $(1,06-10,75))$, pengalaman $(\mathrm{p}=0,01 ; \mathrm{p}<0,05) \mathrm{RP}(4,84 ; 95 \% \mathrm{CI}(1,39-16,8))$, pengetahuan $(\mathrm{p}=0,00 ; \mathrm{p}<0,05)$ RP $(8,12 ; 95 \%$ CI $(2,31-28,5))$ dengan perawatan diri pasien tuberkulosis. Tidak ada hubungan antara pendapatan $(p>0,05)$ dan akses layanan $(p>0,05)$ dengan perawatan diri pada pasien tuberkulosis. Variabel pengetahuan merupakan variabel dominan yang berhubungan dengan perawatan diri pasien tuberkulosis. Disarankan kepada pimpinan Puskesmas Langgapayung mengembangkan program promosi berbasis pengetahuan dengan memperhatikan budaya lokal dalam membina relasi antara petugas kesehatan, keluarga penderita TB, dan penderita TB.
\end{abstract}

Kata Kunci : Tuberculosis, Perawatan Mandiri, Pengetahuan

\begin{abstract}
Tuberculosis is a chronic contagious disease in which Mycobacterium tuberculosis often infects the lungs. In the Langga Payung Puskesmas, Labuhan Batu Selatan Regency in 2018, 266 positive cases of pulmonary TB were found. Of the 266 TB cases, 231 cases (86\%) were new cases and 35 cases (13.1\%) MDR-TB were found. This study aims to analyze factors related to self-care for tuberculosis patients. This study used a cross sectional method with a population of tuberculosis patients who came to the Langgapayung Community Health Center. The sample size was determined by the Lameshow formula as many as 74 new TB cases with the inclusion criteria: Age $\leq 50$ years, have PMO, TB patients have underwent treatment $<2$ months, BPJS health payment system and exclusion criteria: HIV / AIDS, DM, incapacitated, and refused to participate. Samples were drawn by consecutive sampling technique. The research instrument was tested with Corbach alfa and data processing was carried out by logistic regression method at the real level $\alpha=0.05$. The results of the analysis found that there was a relationship between age $(\mathrm{p}=0.04 ; \mathrm{p}<0.05) \mathrm{RP}(3.04 ; 95 \% \mathrm{CI}(1.06-10.75))$, experience $(\mathrm{p}=0.01$; $\mathrm{p}<0.05)$ RP (4.84; 95\% CI (1.39-16.8)), knowledge ( $\mathrm{p}=0.00 ; \mathrm{p}<0.05) \mathrm{RP}(8.12 ; 95 \%$ CI $(2,31-28.5))$ with self-care of tuberculosis patients. There is no relationship between income ( $p>0.05)$ and access to services $(p>$ 0.05 ) with self-care for tuberculosis patients. Knowledge variable is the dominant variable related to self-care for tuberculosis patients. It is recommended that the leaders of Langgapayung Puskesmas develop a knowledge-based promotion program by paying attention to local culture in building relationships between health workers, families of TB patients, and TB patients.
\end{abstract}

Keywords: Tuberculosis, Personal Care, Knowledge 
Sitio Sri Sudewi P, Sembiring Efrata : Analisisi Faktor Yang Berhubungan Dengan Perawatan Mandiri Pasien Tuberculosis

\section{PENDAHULUAN}

\section{Latar Belakang}

Tuberculosis adalah penyakit yang mematikan dan menular. Terdapat 9 juta kasus baru setiap tahunnya dan hampir mencapai 2 juta menyebabkan kematian. Di semua negara telah terdapat penyakit ini, tetapi yang terbanyak di Asia sebesar 55\%, Afrika sebesar 30\% dan untuk India dan China secara tersendiri sebesar 35\% dari semua kasus tubercolosis (WHO, 2011). WHO melaporkan pada tahun 2012 sebanyak 8,6 juta orang terkena TB kasus baru dan 1,3 juta orang diantaranya meninggal. Indonesia merupakan negara dengan pasien TB terbanyak ke-5 di dunia dan berada di urutan 8 dari 27 negara dengan beban TB-MDR terbanyak di dunia (WHO, 2013). Di Indonesia prevalensi kasus TB tahun 2013 terdapat 687.800 kasus baru TB. Tahun 2014, kasus TB di Indonesia mencapai 1.000.000 kasus dan jumlah kematian akibat TB diperkirakan 110.000 kasus setiap tahunnya. Berdasarkan Data Dinas Kesehatan Provinsi Jawa Tengah pada triwulan terakhir tahun 2016, angka penemuan kasus TB yakni 9.378 kasus dengan cakupan kesuksesan pengobatan TB (success rate) hanya mencapai $30,25 \%$ dari angka yang diharapkan $\geq 90 \%$. Kementerian Kesehatan RI (2014) melaporkan ada sekitar 6.900 pasien TB MDR dengan 5.900 orang $(1,9 \%)$ kasus baru dan 1.000 orang (12\%) dari kasus pengobatan ulang. Jumlah penemuan suspek TBMDR di Jawa Barat hingga Oktober 2014 sebanyak 764 orang dengan rincian kasus terkonfirmasi menderita TB MDR sebanyak 303 orang. Dari 203 orang kasus yang mendapatkan pengobatan terdapat 64 orang kasus berada pada fase intensif dan 139 orang fase lanjutan dengan jumlah penderita terbanyak di Bandung (Register TB MDR RSUP DR. Hasan Sadikin Bandung, 2014). Di Provinsi Sumatera Utara jumlah kasus TB BTA+ tahun 2015 mencapai 16.946 kasus meningkat dari tahun sebelumnya sebesar 13.456 kasus (Kemenkes RI, 2015). Persentase pengobatan TB yang dilaporkan pada tahun yang sama sebesar 93,1\% lebih tinggi dibandingkan dengan angka nasional (85\%). Sementara itu di Kabupaten Labuhan Batu pada tahun 2014 ditemukan 2.459 kasus baru TB dan diperkirakan jumlah semua kasus baru dan lama sebesar 2.886 dengan angka success rate sebesar 96,36\%. Dari kasus tersebut ditemukan 106 kasus (3,64\%) TB MDR (Profil Kesehatan Kabupaten Labuhan Batu 2014). Dari hasil study awal di wilayah Kerja Puskesmas Langga Payung Kabupaten Labuhan Batu Selatan tahun 2018 ditemukan sebanyak 266 kasus positif TB paru yang datang berobat ke wilayah Kerja Puskesmas Langga Payung Kabupaten Labuhan Batu Selatan. Dari 266 kasus TB ditemukan sebanyak 231 kasus (86\%) kasus baru dan 35 kasus $(13,1 \%)$ TB-MDR. Penanggulangan Tubercolosis di Indonesia tercantum dalam Peraturan Menteri Kesehatan Republik Indonesia Nomor 67 Tahun 2016, pada Bab II pasal 3 nomor 2 disebutkan bahwa Target Program Penanggulangan TB nasional yaitu eliminasi pada tahun 2035 dan Indonesia bebas TB tahun 2050. Peran Pemerintah dalam menanggulangi TB tercantum pada Bab III pasal 4 nomor 1 tentang kegiatan penanggulangan TB yang berbunyi pemerintah pusat, pemerintah daerah, dan masyarakat bertanggung jawab menyelenggarakan penanggulangan TB. Upaya yang telah dilakukan oleh pemerintah dalam penanggulangan TB yaitu melakukan promosi kesehatan tentang TB pada keluarga atau masyarakat yang terkena kontak dengan pasien TB, mengendalikan faktor resiko dengan memberikan suntik BCG pada bayi untuk mencegah penularan dan meningkatkan kekebalan tubuh, strategi TOSS yaitu Temukan Obati Tubercolosis Sampai Sembuh, serta pemberian OAT secara gratis (Kemenkes RI, 2016). Faktor-faktor penyebab kasus TB RR/TB MDR terus meningkat antara lain belum tersedianya dan belum meratanya Rumah Sakit Rujukan TB MDR dan Rumah Sakit satelit yang melayani kasus TB MDR. Selain itu, faktor lain adalah belum semua Rumah Sakit mempunyai program Directly Observed Treatment ShortCourse (DOTS) yang bagus dan fasilitas pelayanan pengobatan TB belum merata di 34 provinsi. Dari faktor pasien yaitu rendahnya kesadaran diri pasien untuk sembuh dan rendahnya kepatuhan minum obat yang dapat menyebabkan efek samping obat (Infodatin, 
Sitio Sri Sudewi P, Sembiring Efrata : Analisisi Faktor Yang Berhubungan Dengan Perawatan Mandiri Pasien Tuberculosis

2016). Pasien TB membutuhkan waktu 6 bulan dalam pengobatan dan merupakan waktu yang cukup lama dalam suatu rentang pengobatan. Hal ini sangat mempengaruhi keteraturan dan kepatuhan minum obat yang dapat membuat pasien merasa jenuh dan bosan dalam menjalankan pengobatan, kesadaran pasien yang rendah (Kemenkes RI, 2017).

\section{Perumusan Masalah}

Salah satu penyebab rendahnya angka kesuksesan pengobatan TB paru adalah masih rendahnya kesadaran penderita dalam melakukan perawatan kesehatan mandiri secara teratur. Tercapainya target kesuksesan TB Paru yaitu dengan melaksanakan strategi nasional penanggulangan TB, beberapa diantaranya adalah meningkatan kemandirian masyarakat dalam penanggulangan TB dan penguatan manajemen program TB. Beberapa aspek dalam perawatan mandiri yang mempengaruhi tingkat keberhasilan meliputi aspek manajemen minum obat rutin, aspek nutrisi, aspek penanganan stres, aspek pencegahan penularan, dan aspek aktivitas serta istirahat. Hal ini dipengaruhi oleh faktor sosial, ekonomi, tingkat pendidikan, dan budaya masyarakat (Kemenkes RI, 2016).

\section{Tujuan Penelitian}

Hasil penelitian menunjukan bahwa akses kepelayanan (OR 3,4, 95\%CI 1,16-5,06) dan usia (OR 2,6, 95\% 1,13-3,98), pendapatan (OR 2,4, 95\%CI 1,14-4,03), dan pengalaman (OR 1,7, 95\%CI 1,11-4,26) mampu untuk meningkatkan secara signifikan perawatan diri pasien tuberculosis (Lam, 2013).

\section{Manfaat Penelitian}

Perawatan diri dapat meningkatkan kualitas hidup individu dalam kondisi kronis kearah yang semakin baik, menghemat biaya perawatan kesehatan termasuk menurunkan demand pelayanan kesehatan. Meningkatkan kemampuan manajemen faktor risiko, dan penundaan kondidsi yang tidak dinginkan (Ryan, 2017). Davoe (2007) dalam penelitiannya menemukan bahwa faktor usia $(P<0,001)$, pendapatan $(\mathrm{p}<0,000)$, akses ke pelayanan $(\mathrm{p}<0,000)$, health literasi $(\mathrm{p}<0,001)$, dan beban penyakit ganda $(\mathrm{P}<0,001)$ berpengaruh terhadap perawatan diri.

\section{METODE PENELITIAN}

\section{Tempat dan Waktu Penelitian}

Penelitian ini dilaksanakan di Wilayah Kerja Puskesmas Langga Payung Kabupaten Labuhanbatu Selatan.

\section{Alat dan Bahan Penelitian}

Alat yang dan bahan yang digunakan dalam penelitian ini adalah : suntik BCG pada bayi untuk mencegah penularan dan meningkatkan kekebalan tubuh, strategi TOSS yaitu Temukan Obati Tubercolosis Sampai Sembuh, serta pemberian OAT.

\section{Populasi dan Sampel}

Jumlah sampel untuk penelitian ini adalah 74 penderita $\mathrm{TB}$, dimana pengambilan sampel dalam penelitian ini dilakukan dengan menggunakan sampling Non Random dengan cara Consecutive Sampling yaitu penarikan sampel dengan cara menunggu PMO keluarga penderita tuberculosis.

\section{Prosedur Kerja}

Setelah ditetapkan sampel sesuai dengan kriteria yang telah ditentukan, penarikan sampel dengan cara menunggu PMO keluarga penderita tuberculosis yang mendapatkan pelayanan 
Sitio Sri Sudewi P, Sembiring Efrata : Analisisi Faktor Yang Berhubungan Dengan Perawatan Mandiri Pasien Tuberculosis

pengobatan di wilayah kerja Puskesmas Langga Payung Kabupaten Labuhanbatu Selatan. Jika sampel yang ditemukan memenuhi syarat maka dilakukan wawancara hingga jumlah sampel yang ditentukan terpenuhi.

\section{HASIL DAN PEMBAHASAN}

Pengukuran data dalam penelitian ini adalah dengan menggunakan kuesioner. Sebelum dijadikan instrumen (alat ukur), maka kuesioner haruslah sah. Untuk itu perlu dilakukan uji validitas dan uji reliabilitas. Uji validitas dan uji reliabilitas dalam instrument/ kuesioner yang dilakukan pada 15 penderita TB. Uji validitas memakai korelasi Person Product Moment (r), dengan ketentuan, jika $\mathrm{r}$ hitung $>\mathrm{r}$ table, maka dinyatakan valid atau sebaliknya pada taraf nyata $\alpha=0,05$. Dengan nilai item total correlation (CITC). Suatu alat ukur dinyatakan valid jika CITC> 4,6. Uji reliabilitas dengan menggunakan metode Cronbach's Alpha yaitu nilai reliable jika nilai Corbach $\alpha>2,4$ (Notoatmodjo, 2012). Diketahui sampel penelitian dengan 74 penderita TB. Berdasarkan hasil pengolahan dan analisis data dengan metode analisis univariat, analisis bivariat dan miltivariat. Data identitas responden dianalisis dengan menggunakan tabel distribusi frekuensi. Hasil penelitian yang disajikan pada bab ini didapatkan dari pengolahan dan analisis jawaban kuesioner 74 responden di Puskesmas Langga Payung Kabupaten Labuhan Batu Selatan

\section{Hubungan Usia Dengan Perawatan Diri Pasien Tuberculosis}

\begin{tabular}{|c|c|c|c|c|c|c|}
\hline \multirow{3}{*}{ Variabel } & \multicolumn{4}{|c|}{ Perawatan Diri } & \multirow{2}{*}{\multicolumn{2}{|c|}{ Jumlah }} \\
\hline & \multicolumn{2}{|l|}{ Kurang } & \multicolumn{2}{|c|}{ Baik } & & \\
\hline & $\mathrm{n}$ & $\%$ & $\mathrm{n}$ & $\%$ & $\mathrm{~N}$ & $\%$ \\
\hline $\begin{array}{l}\text { Usia (tahun) } \\
>40 \\
\leq 40\end{array}$ & $\begin{array}{l}28 \\
23\end{array}$ & $\begin{array}{l}82,4 \\
59,0\end{array}$ & 16 & $\begin{array}{l}17,6 \\
41,0\end{array}$ & $\begin{array}{l}34 \\
39\end{array}$ & $\begin{array}{l}100 \\
100\end{array}$ \\
\hline $\begin{array}{l}\chi^{2}=3,67 \\
p=0,05 \\
(P>0,05)\end{array}$ & $\begin{array}{l}R P=1,3 \\
9\end{array}$ & \multicolumn{3}{|c|}{$95 \% C I(1,03-1,89)$} & & \\
\hline
\end{tabular}

Berdasarakan tabel diatas dapat dilihat bahwa perawatan diri pasien tuberculosis kurang lebih tinggi ditemukan pada usia $>40$ tahun 28 dara 34 pasien $(92,4 \%)$ dibandingkan dengan usia $\leq 40$ tahun 23 dari 39 pasien (59,0\%). Hasil analisis statistik menunjukan bahwa terdapat hubungan usia dengan perawatan diri pasien tuberculosis di Puskesmas Langgapayung $(\mathrm{p}=0,05 ; \mathrm{p}>0,05)$ dengan rasio prevalensi sebesar 1,$39 ; 95 \% \mathrm{CI}(1,03-1,89)$ yang berarti bahwa risiko penderita tuberculosis mendapatkan perawatan diri kurang 1,03 kali lebih besar pada penderita dengan usia $>40$ tahun dibandingkan pada penderita dengan usia $\leq 40$ tahun.

\section{Hubungan Pendapatan Dengan Perawatan Mandiri Penderita Tuberculosis}

\begin{tabular}{|c|c|c|c|c|c|c|}
\hline \multirow[t]{3}{*}{ Variabel } & \multicolumn{4}{|c|}{ Perawatan Diri } & \multirow{2}{*}{\multicolumn{2}{|c|}{ Jumlah }} \\
\hline & \multicolumn{2}{|c|}{ Kurang } & \multicolumn{2}{|c|}{ Baik } & & \\
\hline & $\mathrm{n}$ & $\%$ & $\mathrm{n}$ & $\%$ & $\mathrm{~N}$ & $\%$ \\
\hline $\begin{array}{l}\text { Pendapatan Keluarga } \\
\leq 2,5 \text { juta } \\
>2,5 \text { juta }\end{array}$ & $\begin{array}{l}46 \\
5\end{array}$ & $\begin{array}{l}68,7 \\
83,3\end{array}$ & $\begin{array}{l}21 \\
1\end{array}$ & $\begin{array}{l}31,3 \\
16,7\end{array}$ & $\begin{array}{l}67 \\
6\end{array}$ & $\begin{array}{l}100 \\
100\end{array}$ \\
\hline $\begin{array}{l}\chi^{2}=0,08 ; \quad p=0,77 \\
(P>0,05)\end{array}$ & $R P=-$ & \multicolumn{3}{|c|}{$95 \% C I(-)$} & & \\
\hline
\end{tabular}


Sitio Sri Sudewi P, Sembiring Efrata : Analisisi Faktor Yang Berhubungan Dengan Perawatan Mandiri Pasien Tuberculosis

Berdasarakan tabel diatas dapat dilihat bahwa perawatan diri pasien tuberculosis kurang lebih rendah ditemukan pada pendapatan keluarga $\leq 2,5$ juta 46 dara 67 pasien $(68,7 \%)$ dibandingkan pada pendapatan $>2,5$ juta 5 dari 6 pasien $(83,3 \%)$. Hasil analisis statistik menunjukan bahwa tidak terdapat hubungan pendapatan keluarga dengan perawatan diri pasien tuberculosis di Puskesmas Langgapayung ( $\mathrm{p}=0,77 ; \mathrm{p}>0,05)$. Dalam hal ini ketahui ketidakadaan hubungan antara pendapatan dengan perawatan mandiri di wilayah kerja Puskesmas langgapayung, Kabupaten Labuhan Batu Selatan.

\section{Hubungan Pengalaman Dengan Perawatan Diri Pasien Tuberculosis}

\begin{tabular}{|l|l|l|l|l|l|l|}
\hline \multirow{2}{*}{ Variabel } & \multicolumn{4}{l|}{ Perawatan Diri } & \multicolumn{2}{l|}{ Jumlah } \\
\cline { 2 - 6 } & Kurang & $\%$ & $\mathrm{n}$ & $\%$ & $\mathrm{~N}$ & $\%$ \\
\cline { 2 - 6 } & $\mathrm{n}$ & & & & & \\
\hline $\begin{array}{l}\text { Pengalaman } \\
\text { Tidak ada } \\
\text { Ada }\end{array}$ & 36 & 81,8 & 8 & 18,2 & 44 & 100 \\
\hline $\begin{array}{l}\chi^{2}=6,15 ; \quad p=0,01 \\
(P<0,05)\end{array}$ & 15 & 51,7 & 14 & 48,3 & 29 & 100 \\
\hline
\end{tabular}

Berdasarakan tabel diatas dapat dilihat bahwa perawatan diri pasien tuberculosis kurang lebih tinggi ditemukan pada pasien yang tidak ada pengalaman 36 dari 44 penderita $(81,8 \%)$ dibandingkan pada pasien yang ada pengalaman 15 dari 29 pasien $(51,7 \%)$. Hasil analisis statistik menunjukan bahwa terdapat hubungan pengalaman dengan perawatan diri pasien tuberculosis di Puskesmas Langgapayung $(\mathrm{p}=0,05 ; \mathrm{p}<0,05)$ dengan rasio prevalensi sebesar 1,$58 ; 95 \% \mathrm{CI}(1,08-2,30)$ yang berarti bahwa risiko penderita tuberculosis mendapatkan perawatan diri kurang 1,58 kali lebih besar pada penderita tidak ada pengalaman dibandingkan pada penderita dengan ada pengalaman.

\section{Hubungan Pengetahuan Dengan Perawatan Diri Pasien Tuberculosis}

\begin{tabular}{|c|c|c|c|c|c|c|}
\hline \multirow[t]{3}{*}{ Variabel } & \multicolumn{4}{|c|}{ Perawatan Diri } & \multirow{2}{*}{\multicolumn{2}{|c|}{ Jumlah }} \\
\hline & \multicolumn{2}{|c|}{ Kurang } & \multicolumn{2}{|c|}{ Baik } & & \\
\hline & $\mathrm{n}$ & $\%$ & $\mathrm{n}$ & $\%$ & $\mathrm{~N}$ & $\%$ \\
\hline $\begin{array}{l}\text { Pengetahuan } \\
\text { Kurang } \\
\text { Baik }\end{array}$ & $\begin{array}{l}42 \\
9\end{array}$ & $\begin{array}{l}84,0 \\
39,1\end{array}$ & $\begin{array}{l}8 \\
14\end{array}$ & $\begin{array}{l}16,0 \\
60,9\end{array}$ & $\begin{array}{l}50 \\
23\end{array}$ & $\begin{array}{l}100 \\
100\end{array}$ \\
\hline $\begin{array}{l}\chi^{2}=13,0 ; \quad p=0,00 \\
(P<0,05)\end{array}$ & $R P=2,14$ & \multicolumn{3}{|c|}{$95 \% C I(1,27-3,62)$} & & \\
\hline
\end{tabular}

Berdasarakan tabel diatas dapat dilihat bahwa perawatan diri pasien tuberculosis kurang lebih tinggi ditemukan pada pasien dengan pengetahuan kurang 42 dari 50 penderita $(84,0 \%)$ dibandingkan pada pasien dengan pengetahuan baik 9 dari 23 pasien $(39,1 \%)$. Hasil analisis statistik menunjukan bahwa terdapat hubungan pengetahuan dengan perawatan diri pasien tuberculosis di Puskesmas Langgapayung $(\mathrm{p}=0,00 ; \mathrm{p}<0,05)$ dengan rasio prevalensi sebesar 2,14; 95\%CI $(1,27-3,62)$ yang berarti bahwa risiko penderita tuberculosis mendapatkan perawatan diri kurang 2,14 kali lebih besar pada penderita dengan pengetahuan kurang dibandingkan pada penderita dengan pengetahuan baik 
Sitio Sri Sudewi P, Sembiring Efrata : Analisisi Faktor Yang Berhubungan Dengan Perawatan Mandiri Pasien Tuberculosis

\section{PEMBAHASAN}

Dari hasil penelitian ditemukan bahwa semakin muda usia seorang penderita tuberculosis maka perawatan diri dalam pengontrolan pengobatan, kontrol lingkungan, dan kontrol droplet nuclei akan semakin baik. Selain itu diketahui bahwa 91,8\% penderita tuberculosis termasuk kedalam golongan pendapatan rendah. Sehingga terjadi penurunan daya beli dan berkontribusi terhadap kurangnya pemenuhan status gizi penderita tuberculosis. Selain itu akses jarak yang ditempuh mencapai $15 \mathrm{~km}$ dari masyarakat Langgapayung, Kabupaten Labuhan Batu Selatan hal ini berpengaruh terhadap pendistribusian obat penderita tuberculosis. Diketahui kurangnya pengalaman penderita tuberculosis dengan perawatan diri yang menyebabkan tingginya kasus tuberculosis. Hal ini terjadi karena penyakit tuberculosis masih dianggap penyakit tuberculosis sebagai aib, sehingga kasus ini sering disembunyikan, Hal ini terjadi akibat kurangnya informasi kesehatan dalam konteks perawatan diri penderita tuberculosis. Dimana ketika ditemukan penderita tuberculosis hanya berfokus pada pencarian pengobatan jika terjadi sakit, Konteks pemahaman ini perlu dirubah. Dimana perawatan diri penderita tuberculosis melihat kepada kelengkapan informasi pelayanan yang diterima oleh penderita, kemungkinan atau probabilitas kesembuhan dari penyakit yang sedang diderita, dan jika suatu perilaku tersebut diikuti, maka perlu ada kemampuan fisik dan biaya yang harus ditanggung untuk melakukan perawatan diri tersebut.

\section{KESIMPULAN}

Diketahui dari 74 penderita TB di Puskesmas Langga Payung Kabupaten Labuhan Batu Selatan diketahui terdapat hubungan usia dengan perawatan diri pasien tuberculosis, dimana semakin muda penderita ketanggapan dalam perawatan diri lebih besar daripada usia lanjut. Hubungan pengalaman pasien terhadap perawatan diri pasien tuberculosis masih kurang sejalan dengan kurangnya pengetahuan penderita tuberculosis. Namun untuk hubungan pendapatan dan akses ke pelayanan dengan perawatan diri pasien tuberculosis di wilayah kerja Puskesmas Langgapayung tidak terdapat hubungan. Maka diperoleh kesimpulan bahwa pengetahuan adalah variabel yang dominan berhubungan dengan perawatan diri pasien tuberculosis di Wilayah Kerja Puskesmas Langgapayung, Kabupaten Labuhan Batu Selatan.

\section{DAFTAR PUSTAKA}

DeVoe, J.E; Baaez, A; Angier, H; Krois, L; Edlund, C; Carney, P.A (2007). "Insurance + access $\neq$ health care: typology of barriers to health care access to low-income families". Annals of Family 518. doi:10.1370/afm.748. PMC 2094032. PMID 18025488.

Dinas Kesehatan Labuhan Batu Selatan, 2014; Profil Kesehatan Kabupaten labuhan Batu Tahun 2014

Kemenkes RI, 2014; Peraturan Menteri Kesehatan Republik Indonesia Nomor 565/Menkes/Per/Iii/2011 Tentang Strategi Nasional Pengendalian Tuberkulosis Tahun 2011-2014. Dapat diakses di http://www.searo.who.int/indonesia/topics/tb/stranas_tb2010-2014.pdf

Kemenkes RI, 2016; Peraturan Menteri Kesehatan Repubelik Indonesia No. 67 Tahun 2016 Tantang Penanggulangan Tuberculosis. Dapat Diakses di http://www.tbindonesia.or.id/tbident/uploads/2017/11/Permenkes-No.67-TB-tahuh2017.pdf

Kemenkes RI, 2017; Data dan Informasi Profil Kesehatan Indonesia Tahun 2016.Pusat Data dan Informasi. Kementerian kesehatan RI 2017 
Sitio Sri Sudewi P, Sembiring Efrata : Analisisi Faktor Yang Berhubungan Dengan Perawatan Mandiri Pasien Tuberculosis

Lam, C; Smeltzer, S.C (2013). "Patterns of symptom recognition, interpretation, and response in heart failure patients: An integrative review". Journal of Cardiovascular Nursing. 28 (4): 348-359. doi: $10.1097 / \mathrm{jcn} .0 \mathrm{~b} 013 \mathrm{e} 3182531 \mathrm{cf}$. PMID 22580629.

Notoatmodjo, Soekidjo.(2012). Promosi Kesehatan dan Perilaku Kesehatan. Jakarta: Rineka cipta.

Ryan (2017). "Chronic disease management: what will it take to improve care for chronic illness?". Eff Clin Pract. 1 (1): 2-4. PMID 10345255

World Health Organization, (2011). Dalam: Departemen Kesehatan Republik Indonesia, Pedoman Penanggulangan Tuberkulosis. Jakarta

World Health Organization. (2013). Tuberculosis : WHO Global Tubercolosis Report. Fathsheet : World Health Organization

\begin{tabular}{|l|l|l|l|}
\hline Accepted Date & Revised Date & Decided Date & Accepted to Publish \\
\hline 09 November 2020 & 10 November 2020 & 17 November 2020 & Ya \\
\hline
\end{tabular}

